\title{
MOVIMENTOS SOCIAIS E ONG'S NA CONSTRUÇÃO DAS POLÍTICAS PÚBLICAS E DA ÉTICA CIDADÃ
}

Maria Esther Barbosa Dias'

O presente ensaio objetiva estudar, ainda que de maneira breve, o complexo processo de construçáo de una ética cidadã de recorte relativamente inédito, através da intervenção dos movimentos sociais na produção das políticas públicas ao longo das duas últimas décadas, considerando-se sua permanente relação de interlocução c conflito com o Estado e, a partir sobretudo dos anos 80 , com as chamadas organizaçōes não-governamentais (ONG's).

Na travessia da reflexão - e aqui nos beneficiamos da conhecida formulação de (iumaráes Rosa quanto à existência do real como processo, como travessia -, nossa análise deságua nos anos 90, ctapa extremamente significativa da história brasileira em que se configura um novo conário das lutas sociais, observados os cenários da chamada globalização da economia, ao mesmo tempo en que, via de consequiencia, se reelaboram as pautas analíticas trabalhadas pelos pesquisadores da árca. Com esta nota, concluiremos nosso estudo.

\section{O REAL ESTÁ NA TRAVESSIA (APUD GUIMARÃES ROSA)}

Na Europa, fonte permanente de inspiração para o pensamento crítico dos intelectuais brasileiros, a presenca dos chamados novos movimentos sociais dos anos 70 exigiu abordagens qualitativanente

\footnotetext{
1 Professora Visinate do Mestrado em Sociologia da IJFCE.
} 
inéditas por parte dos investigadores que se posicionam no campo das Ciências Sociais. Década de grande cfervescência política e cultural, os anos 70 trouxeram 'novidades' que foram captadas con clareza por um conjunto de estudiosos. Nesse sentido, destacam-se os trabalhos de grande relevância teórico-prática como os elaborados por Lojkine, Castells, Borja, Touraine, Castoriadis, Melluci, Tilman e Giattari.

A produção desses estudiosos debruçou-se, sobremaneira, sobre o impacto das novas formas de ação coletiva, em um espaço urbano marcado pela recorrente crise do capitalismo, como acentua Castells. Estudiosos como (inattari, por seu turno, traballharan a partir de abordagens inéditas sobre esse cotidiano, muitas vezes sob forte influência de uma leitura crítica da Psicanálise. Destaca-se entre elas a perspectiva das novas 'cartografias', o desejo individual e coletivo, as micropolíticas - en síntese, a "revoluçáo molecular', de notável impacto sobre análises posteriormente desenvolvidas no Brasil, inclasive acerca da aça dos partidos políticos.

Em nosso País, os estudos realizados nos anos 70 sobre os movimentos sociais brasileiros e latino-americanos, especialmente en nível urbano, foram influenciados pela sociologia marxista francesa. laz-se imprescindível assinalar, no entanto, que oflorescincnto dessa pesquisa e a construção de seus vínculos teórico-práticos, levaram, com o passar do tempo, a um relativo afastancnto dos referenciais "importados", sem, contudo, perdê-los inteiramente de vista. Nessa óptica, cabe destacar a produçà de Eruesto Laclan, Lúcio Kowarick, Eder Sader, José Álvaro Moisés, Ruth (ardoso, Funice Durham, Ilze Scherer-Warren, Maria da Cilória Gohn, Vera Telles, entre outros exemplos do rosto latino-anericano na pesquisa dessa temática.

Em termos cronológicos, ofinal dos anos 70 assinalou o aparecimento dos primeiros estudos enfocando a 'novidade' dos movimentos sociais, ou seja,

"a ampliação qualitativa do aspecto reivindicativo e sua significaçăo mais profunda en face ao tempo histórico que se vivia".

Enquanto na década anterior, os novimentos sociais eram ana- 
lisados a partir do bloqueio dos canais tradicionais de expressão (partidos políticos c sindicatos, cntre outros), por parte do regime autoritário, ao final da década de 70 e ao longo da seguinte, vivendo-sc o cenário da "abertura lenta, segura e gradual", patrocinada pelo governo Creisel, o cufoque das análises deslocou-se para o

"aspecto reivindicativo cualitativanente superior desses movimentos que, em alguns casos, consegniram ultrapassar o mero enunciado da reivindicação, caminhatido em direção à proposiçäo de dircitos e sla eferiva concretização em uma perspectiva mais ampla direcionada para a conculista da cidadania".

Novos tempos históricos exigiam novas modalidades de intervençáo coletiva cos movimentos fizeram-se presentes no cenário do tortuoso retorno ao Estado de direito.

$\dot{E}$ a partir dessa conjuntura, observado o pano de fundo estrutural, que se consegue encontrar caminhos qualitativạmente inéditos para se clucidar a emergência desses movimentos. O aprofundamento da questáo social -

"a diviscĩo da sociedade cm classes e a luta pela apropriação da riprozal socialmente produzida, en um cenário de graves desigualdades e degradação continuada das condiçốes de vida de uma imensa parcela da populaçấ brasileira"

- constituiu elemento impulsionador dos movimentos sociais em seu sentido mais amplo, bem como das várias organizaçóes da sociedade civil que se atribuíram à tarefa de contribuir, para dar concretude cada vez maior a essa pauta de demandas. Náo se pode esquecer o fato que cssa efervescência contribuiu, em grande medida, para a configuração da atual Constituição da República (1988): afinal de contas, foram recolhidas 12 milhóes de assinaturass às emendas populares, um processo rigorosamente incédito de co-autoria do texto constitucional.

- Dessa forma, o elenento conum que explica o surgimento e afirmação desses movimentos sociais pode ser encontrado na busca, 
"inicialmente individual e posteriormente coletiva, de soluçós para os problemas jả apontados. Essa busca passa obrigatoriantente pela formulação e execução de políticas públicas básicas, sistemática e cocrentemente construídas, cujo usufruto seja capaz de elevar significativamente a condiçăo de vida das classes sociais postas à margen do gozo dos bens, serviços e direitos produzidos pela sociedade contcmporânea".

É precisamente nesse sentido que o Estado ć colocado como interlocutor obrigatório dos movimentos sociais, tendo nas políticas públicas um de seus campos de luta. Essa interlocução inclui, igualmente (e de forma necessária), as diversas fraçóes do capital envolvidas na permanente construção dos diversos espaços sociais e no controle desse nesno Estado. Trata-se, afinal, de um processo inerente às sociedades que vivem sob a hegemonia capitalista ${ }^{2}$. A literatura nais recente indica que esses movimentos se caracterizaram, sobretudo nesse momento específico, por uma dinânica que só se explicaria historicamente em certas "situaçōes de crisc", quando o Estado (e os interesses que representa) não se encontra em situação hegemonica para ignorar ou responder (concreta on retoricamente) às necessidades c pressôes a cle dirigidas. "A negociaça assume obrigatoriamente espaços significativos na cena política".

\section{Os 'TROPECOS' DA TRAVESSIA}

Compre, aqui, reafirmar a importancia do Estado no que diz respeito ao seu papel de principal produtor e gestor dos bens e serviços que compóem o universo das políticas públicas. Sabemos que essas políticas têm fincionado de forma ambígu, como "perspectiva de aco-

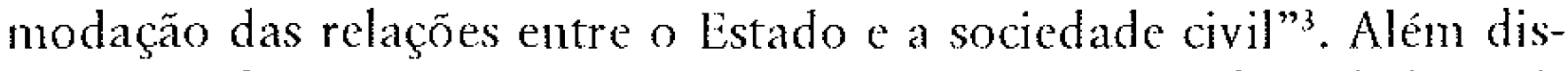
so, tais políticas têm se caracterizado por sua pouca efetividade social, elevado custo financeiro c acentuado grau de desperdício material,

2 Ver MOISÉs, J. A, (Org.) Cidade, Povo e Poder. Rio de Janciro, Paz c Terra / CEDEC, 1982. JACOBI, P, Movimentos Sociaris a Politicus Páblicas, São Paulo, Cortez, 1989. É igualmente importante a consult ta ao ensaio "As Políticas Sociais Brasileiras: Diagnósticos e Perspectivas". DRAIBE, Sônia Miriam. In Para a Dearde de 90; Prioridades e Perspectivess de Politicas publicas (volume 4). Brissília, IPEA/PI.AN, 1990.

${ }^{3}$ YASBEK, M. C., Classes Suballermas e Assistência Sorial. Sño Paulo, Cortez, 1993:35. 
bem como por uma enome subordinação aos interesses econômicos que marcam os investimentos do Estado brasileiro, inclusive nessa esfera.

A relação dos movimentos sociais com o Estado apresenta uma trajetória

"que assume, ao longo do tempo, diversas metamorfoses, indo da relação 'f́lial' perante o Estado pai-patrão, à negociação e, fimalmente, à iztervenção de forma mais organizada, no sentido da claboraçăo de políticas sociais e gradativa gestão de espaços no espaço urbano, locas do confronto com um Fstado privatizado, condomínio do grande apital"'.

Nesse cenário, é fundamental assinalar que a privatização do Estado, em benefício do capital, significa o atrelamento da oferta de bens e serviços de consumo coletivo básico (inclusive os de infra-estrutura) às necessidades da acumulação. Desse modo, a ação do Estado, no campo das políticas públicas, reveste-se de uma dupla e permanente tensão, expressão do conflito estrutural presente em uma sociedade de classes.

Tem-se, de um lado, as diversas fraçoes do capital, privatizando o Estado e utilizando-o cm função de seus interesses na esfera da acumulação. Pense-se, por exemplo, nas faraônicas obras de infra-estrutura começadas nos anos 70 e posteriormente abandonadas (Transamazônica, Ferrovia do $\Lambda$ ço, etc.), sem que tenha ocorrido o ressarcimento dos fundos públicos mal aplicados nesses investimentos.

De outro, em contraponto, a pressão, em graus variados de consistência, da

"rede cada vez mais complexa dos movimentos sociais demandan" do investimentos substanciais em saúde, edıcação, transporte, habitação e segurança".

${ }^{4}$ DIAS, José Fernandes, Derrubando os 'Muros de Berlim': Movimenlos Sociais Unbanos no Brasil Conlemporâneo, Mutaçốs Sociais, CEDAC, Rio de Janeiro, ano 1, n". 1, juihol setembro de 1992. 
Nesse sentido, Francisco de Oliveira aponta, com clareza, o mecanismo de regulação ad hoc, casuística, posta cm marcha pelo Estado brasileiro para 'resolver' esse conflito, repita-se, estrutural's.

\section{UM INTERLÚDIO NA TRAVESSIA: A ÉTICA CIDADÃ}

() extraordinário florescimento dos debates acerca da ética na política dá-se, sobretudo, ao longo da conturbada década de 80 , por razôes sobejamente conhecidas e sintetizadas na tristemente emblemática figura do ex-presidente Collor e em seu breve e cático (des)governo. Surge daí a indagação: ética cidadã, onde é o seu território? Será ético um discurso político que promete o bem, do alto, sem denunciar a mentira de base que o construiu? Onde fica a ética do discurso de quem promete modernizar o Estado se não sabe (ou não quer?) promover a reforma agrária? "Ética cidadā não se discute, pratica-se".

Estamos falando aqui, reiteramos, da ética no exercício da política. Se desejarmos, de fato, contribuir para que ela se estabeleça como prática cotidiana, há que se assinalar que na ética cidadã, o que deve prevalecer é a qualidade dos valores e das práticas sociais postas $\mathrm{cm}$ marcha, com vistas à construção de um projeto de sociedade que tenha como fundamentos não a predatória acumulaçáo do capital mas, sim, a luta permanente pela justiça social e pelo fim de todas as modalidades de exclusão econômica, política, social e cultural.

Nesta perspectiva, a prática da ética cidadáa não depende micamente do lugar que cada um ocupa no universo das relaçóes de produção mas, acima de tudo, de uma compreensão correta acerca das demandas sociais das maiorias excluídas, concretizada através da coerência entre discurso e prática. Destacamos a importância, muitas vezes amesquimhada no discurso pretensamente progressista, dos valores éticos (e sua expressão concreta) que inspiram cada um em relação à sociedade que afirma querer construir. Aqui, o terreno da ética

5 OLIVEIRA, Francisco de, Os Protagonistas do Dramm: Estado e Sociedade wo Brasil. In LARANJEIRA, S., (Org.) Classes Sociais r Movinentos Sockigis ma América Latim. São Paulo, IUCITEC, 1990: 43-46. 
cidadá representa, nas palavras de Herbert de Souza, Betinho, protagonista fundamental do Movimento pela Ética na Política e da Ação da Cidadania contra a Fome, a Miséria e pela Vida, "o berço do novo e a redenção da política como parteira da utopia". Foi em nome da ética cidadá ou ética na política, que se gestou o que se pode chamar de conduta coletiva da indignação da era Collor. Este tipo de conduta despertou um movimento em nivel nacional, acima referido, que desempenhou papel de relevo na admissibilidade do impeachment do então presidente da República, recurso jamais aplicado em toda a história do País.

\section{NOVOS SINAIS NA TRAVESSIA}

As grandes transformaçóes sofridas pelo Brasil nestes anos da década de 90, sobretudo o impacto dos processos de estabilização monetária trazida pelo Plano Real ${ }^{7}$ (vetor, em nível interno, da crescente e acelerada inserção da economia e da sociedade aos processos da chamada globalização ${ }^{8}$ ), desenharam um novo perfil para os movimenros sociais e ampliaran a visibilidade das ONG's a que fizemos breve referência até agora.

Chama-nos a atenção, de um lado, o fato de os movimentos sociais - à notável e solitária exceção do Movimento dos Trabalhadores Rurais Sem Terra (MST) - parecerem perder fôlego se comparados ao ímpeto da década precedente, 'competindo' com o retorno de atores tradicionais como os partidos políticos, sindicatos e centrais

\footnotetext{
"Ver, a respeito, JACOBI, P., Pela Açõo da Cidadania contra a Fome, a Miséria e pela Vida, Proposta, FASE, $\mathrm{n}^{\circ}$. 67, dezembro de 1995.

${ }^{7}$ Para uma leitura crítica acerca do Plano Real, consultar DIAS, José Fernandes, Cemúrios da Coninatura, minneo, 1996. Do mesno antor, consultar Trabalbo, Renda ér Cidadaniar no Brasil, mineo, 1997.

* Acreditanos ser conceitualmente correto denominar esse processo de 'internacionalização' e não 'globalização', uma vez que, segundo dados da Organização Internacional do Trabatho (OIT), existem atualmente en todo o planeta cerca de um bilhão de seres humanos desenpregados e sub-empregados. Com esse contingente equivalente a $20 \%$ da população da Terra, como se poderá falar de globalização? Consultar, a respeito, DIAS, José Fernandes. Irabalbo, Renda pio Cidadaria no Brasil, op. cit.
} 
Nesse sentido, Francisco de ()liveira aponta, com clare\%a, o mecanismo de regulação ad hoc, casuística, posta em marcha pelo listado brasileiro para 'resolver' esse conflito, repita-se, estrutural'.

\section{UM INTERLUUDIO NA TRAVESSIA: A ÉTICA CIDADÃ}

() extraordinário florescimento dos debates acerca da ética lla política dá-se, sobretudo, ao longo da conturbada década de 80, por razões sobejamente conliecidas e sintetizadas na tristemente emblematica figura do ex-presidente (ollor e en seu breve c cacótico (des)governo. Surge daí a indagação: ética cidadá, onde é o seu território? Será ético um discurso político que promete o bem, do alto, sem denunciar a mentira de base que o construiu? ()nde fica a ética do discurso de quem promete modernizar o listado se não sabe (ou näo) quer?) promover a reforma agrária? "Ética cidadá não se discute, pratica-se".

Estamos falando aqui, reiteramos, da ética no exercício da política. Se desejarmos, de fato, contribuir para que ela se estabeleça como prática cotidiana, há que se assinalar que na ética cidadã, o que deve prevalecer é a qualidade dos valores e das práticas sociais postas cm marcha, com vistas à construção de um projeto de sociedade que tenha como fundamentos não a predatória acumulação do capital mas, sim, a luta permancnte pela justiça social e pelo fim de todas as modalidades de exclusão econômica, política, social e cultural.

Nesta perspectiva, a prática da ética cidadã não depende unicalmente do lugar que cada um ocupa no universo das relaçōes de produção mas, acima de tudo, de uma compreensão correta acercal das demandas sociais das maiorias excluídas, concretizada através da (o)erência entre discurso e prática. Destacamos a importancia, muitas vezes amesquinhada no discurso pretensamente progressista, dos vallores éticos (e sua expressão concreta) que inspiram cada um cm reliação à sociedade que afirma querer construir. Aqui, o terreno da ética

5 OLIVEIRA, Francisco de, ()s Prolagonistas do Drama: Fslado "Sociredade no Brasil. In I.ARANJEIRA, S., (()rg.) Classes Sociais e' Movimemtos Soriais ma dmernca l.atima. São Paulo, HIICITEC; 1990): 4.3-46. 
cidadã representa, nas palavras de Herbert de Souza, Betinho, protagonista fundamental do Movimento pela Ética na Política e da $\Lambda$ ção da (idadania contra a lome, a Misćria e pela Vida, "o berço do novo c a redenção da política como parteira da utopia" Foi em nome da ética cidadã ou éticia na política, que se gestou o que se pode chamar de conduta coletiva da indignação da era (collor. Este tipo de conduta desperton um movimento em nível nacional, acima referido, que desempenhou papel de relevo na admissibilidade do impenchment do então presidente da República, recurso jamais aplicado em toda a histoirial do l'ais.

\section{NOVOS SINAIS NA TRAVESSIA}

As grandes transtormaçōes sofridas pelo Brasil nestes anos da década de 9(), sobretudo o impacto dos processos de estabilização moncetária trazida pelo llano Real7 (vetor, em nivel interno, da crescente e acelerada inserção da economia e da sociedade aos processos da chamada globalizaçãa $\left.{ }^{8}\right)$, descuharam um novo perfil para os movimentos sociais e ampliaram a visibilidade das ()NG's a que fizemos breve referência até agora.

(hama-nos a atenção, de um lado, o fato de os movimentos sociais - à notável e solitária exceção do Movimento dos Trabalhadores Rurais Sem Terra (MST) - parecerem perder fôlego se comparados ao impeto da década precedente, 'competindo' com o retorno de atores tradicionais como os partidos políticos, sindicatos e centrais

\footnotetext{
"Ver, a respeito, JA(:) ()BI, P., Pela Açio da Cidadania contra a Fome, a Miséria e pela Vida, Iropostu, MASt: $n^{\circ} .67$, dezembro de 1995.

Para uma leitura crítica acerca do Plano Real, consultar DIAS, Jose Fernandes, Cénúrios da Conjumtura, mimeo, 1996. Do mesmo autor, consultar Trabalbo, Renda è Cidadamia "10 Brasil, mimeo, 1097.

* Acreditamos ser conceitualmente correto denominar esse processo de 'internacionalização' ' nào 'globalizaçĩo', uma ve’z que, segundo dados da Organização Internacional do Trabalho (()IT), existem atualmente em todo o planeta cerca de um billià de seres humanos desempregados e sub-empregados. Com esse contingente equivalente a $20 \%$ da população da 'lerra, como se poderá falar de globalização? ('onsultar, a respeito, DIAS, José Fernandes.

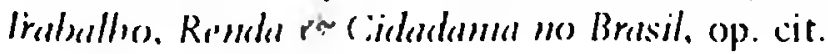


sindicais, e tendo que conviver com uma significativa 'anestesia' social trazida pela chamada estabilização monetária, já referida.

Por outro, amplia-se a interlocução com as ONG's, que adquirem maior visibilidade nas lutas pela cidadania, uma vez vencido o período de relativa 'clandestinidade', que caracterizou parcela significativa de sua atuaçáo em razão dos mecanismos repressivos ainda atuantes até a metade dos anos 80. Cabe indagar: afinal de contas, 0 que são essas tão faladas organizações não-governanentais? () que têm a dizer nos novos panoramas que se abrem ao fazer político da cidadania na travessia da década derradeira do século 20?

Para alguns analistas, as ONG's surgem como 'substitutas' dos movimentos sociais. Outros conseguem vê-las de mancira claramente diferenciada em face a esses movimentos. O certo é que constituem um fenômeno mundial, quer em países capitalistas, quer em países em nítido processo de transição para as economias de 'mercado', como a Rússia. Canadá, Estados Unidos, França, Nemanha, Holanda, Espanha e Bélgica são os países de presença mais significativa dessas Entidades.

A denominação 'organização náo-governamental' (ONG)

"foi criada pela ONU em 1940, para designar entidades não oficiais que recebian ajuda financeira de órgãos públicos para executar projetos de interesse socjal dentro de nima filosofia de trabaho de 'desenvolvimento de commidade'. O recorte da definição da ONU é dado pela estrutura jurídica: ser ou năo ser governo. As ONCi's se localizam tha esfera do privado"

Em nosso País, o denominador comum das ONG's é a razão social de sua constituição como instituição da sociedade civil que se declara sem fins lucrativos, tendo geralmente como objetivos "apoiar, incentivar e assessorar causas coletivas em termos de projetos".

Em seus estudos e pesquisas sobre as ONG's, Maria da Gló-

9 GOHN, M. da Glória, Movinnenlos, ONG's e Lulas Soctatis wo Brasil wos amos 90, XIX Encontro Nacional da ANPOCS, Caxambu, 1995. 
ria Gohn ${ }^{10}$ divide-as em três campos: Filantropia, Desenvolvinentismo e Cidadania. O campo da Filantropia é o mais antigo, representado por entidades que no início do século prestavam assistência às populaçóes ditas 'carentes', quando a questāo social ainda era considerada "questão de polícia'"

"O campo do desenvolvimentisno data do pós-guerra. Neste período, cumba-se a expressáo 'sem fins lucrativos' para designar uma categoria de instituiçôes não voltadas para o licro, tendo como público alvo os setores carentes financeiramente, envolvidos cm projetos de desenvolvimento econômico local. (...) Grande parte das ONG's da América Latina surgiu nos anos 70 e se enquadram, un sua grande maioria, na modalidade desenvolvimentista"'

O campo da 'cidadania' é o mais recente e emergin no seio dos movimentos sociais da última década, tendo como raiz a luta de organizações da sociedade civil pelos direitos individuais c coletivos, tendo como centralidade a temática concreta das políticas públicas. Merece destaque o novo papel das ONG's, à medida em que, com o fim do regime ditatorial, a correlação de forças entre o Estado e a socicdade civil passa por mudanças significativas. Trata-se de uma etapa qualitativamentc nova da sociedade brasileira, com a ênfase representada pela tensão permanente entre as 'velhas' questóes estruturais e as 'novas' demandas de um mundo em transformaçáo, acelerada pelo vetor da internacionalização da cononia e suas conseqüências para o cotidiano dos cidadãos.

Em face a esse universo em impressionante mutação, os técnicos das ONG's sentiram necessidade de ampliar a sua capacitação e também desenvolver parcerias com outras entidades, governamentais ou não, como as Universidades, no sentido da elaboração de projetos de

\footnotetext{
${ }^{10}$ Idem, p. 32 .

II Cabe indagar, en face aos massacres de trabalhadores rurais (Eldorado de Carajás, Corumbiara, etc.) e traballyadores urbanos (Carandin, Vigário Geral, Diadema, etc.) se a quuestão social ainda não é vista por parcela significativa da sociedade brasileira como verdadeira "questão de polícia".
}

${ }^{12}$ Widem. 
orientação comum, capazes de responder a exigências cada vez mais complexas, sinalizadas pelo fazer político dos diversos atores sociais, sobretudo, as organizaçoes populares. Em muitos casos, profissionais da academia passaram a prestar assessoria às ONG's, o que pode ser comprovado por inumeras publicaçoes e pesquisas.

Por razôes de estratégia política global, o próprio Banco Mundial tem dado crescente atençấo às ONG's desde a década de 80 , sobretudo no campo ambicntalista, priorizando o desenvolvimento de açōes em parceria com essas entidades, sob a alegaçáo de considerálas mais eficientes que as agências governamentais. Considerando-se a trajetória e o papel estratégico do Banco Mundial em face aos processos da internacionalização da economia, tudo parece indicar que esse 'novo' posicionamento apresenta-se muito mais como uma tentativa (em maior on menor escala) de cooptação de setores críticos da sociedade civil, do que uma mudança qualitativa da Instituição em face a $u m$ universo de questóes extraordinariamente relevantes em escala planetária.

Em nosso País, um grande número de ONG's passou a ter mais destaque a partir da II Conferência das Naçoes Unidas para o Desenvolvimento, popularmente conlecida como "EC() 92", evento em que essas entidades desempenharan un papel importante, no sentido de simbolizar a participação e os anseios da sociedade civil organizada. As demais Conferencias da ONI que se seguiram a 1992, sobretudo aquelas onde se debateran examstivamente as questóes de população e do universo feminino (Cairo a Beijing), das estrategias mundiais para o desenvolvimento sustentável (Copenhague) e para a questão urbana (Istambul), contaram igualmente com forte presença das ONG's.

Un outro dado que tem contribuído para uma maior visibilidade do papel dessas entidades no cenário brasileiro, diz respeito às importanfes pesquisas que menbros de várias ()NG's, notadamente aquelas dotadas de maiores recursos, vêm realizando ao longo dos últimos anos. Merecem destaque os trabalhos realizados pelo PÓLIS, pelo CEDEC e o CEBRAP, cm São Paulo, bem como o IBASE e a FASE, no Rio de Janeiro, notadamente na esfera das políticas públicas, materiais de crescente importância para o fazer político dos movimentos sociais. 
Em síntese, podemos afirmar que as ONG's representam formas modernas de participação e luta na sociedade pelos chamados direitos sociais. Elas também podem servir de mediação em políticas realizadas em parceria, que articulen a ação do Estado e da populaçióo organizada, em projetos específicos na esfera das políticas públicas. Por fim, as ONCis, desde que observem rigorosamente seu papel de interlocutores na construção da estera pública democrática, podem representar a possibilidade de interconexáo permanente com suas congêneres c, acima de tudo, com os movimentos sociais a que prestam assessoria. Aqui, faz-se imprescindivel a concretizaçáo da constimiçáo de redes que representem propostas democráticas pautadas pela lógica da participação e da decisão entre iguais. Somente assim, as ONG's afirmaram selu carátcr de interlocutoras e náo correrāo o risco de se tornarem fins em si mesmas, a partir de processos internos de burocratizaça e esmaecimento do diálogo democrático.

5. UMA 'PAUSA' NA TRAVESSIA: NOSSO PAPEL NA INTERLOCUÇ̃̃O DEMOCRÁTICA

Realizar estudos e pesquisas com os recursos da metodologia comparativa tem sido o caminho adotado por vários pesquisadores no campo das Ciências Sociais. (comparar cenários, desempenho de atores, demarcar as diferenças e, especialmente, captar as tendências pode ser o caminho estratégico e fundamental para realizarmos pesquisas neste final de seculo, sem deixarmos de lado, no universo da internacionalização da economia, as peculiaridades históricas locais do ponto de vista economico, social, político e cultural. A finalidade da comparação náo é tão somente a possibilidade de produção e generalização a partir dos pontos commons mas, sobretudo, no sentido de apontar diferenças capazes de sinalizar novos caminhos a serem percorridos, na perspectiva infatigável da construção da democracia em nosso País, com a superação de todas as formas de exclusão social ainda existentes em nossa sociedade. 